\title{
Nocturnal Light Exposure Impairs Affective Responses in a Wavelength-Dependent Manner
}

\author{
Tracy A. Bedrosian, Celynn A. Vaughn, Anabel Galan, Ghassan Daye, Zachary M. Weil, and Randy J. Nelson \\ Department of Neuroscience, Ohio State University Wexner Medical Center, Columbus, Ohio 43210
}

Life on earth is entrained to a $24 \mathrm{~h}$ solar cycle that synchronizes circadian rhythms in physiology and behavior; light is the most potent entraining cue. In mammals, light is detected by (1) rods and cones, which mediate visual function, and (2) intrinsically photosensitive retinal ganglion cells (ipRGCs), which primarily project to the suprachiasmatic nucleus (SCN) in the hypothalamus to regulate circadian rhythms. Recent evidence, however, demonstrates that ipRGCs also project to limbic brain regions, suggesting that, through this pathway, light may have a role in cognition and mood. Therefore, it follows that unnatural exposure to light may have negative consequences for mood or behavior. Modern environmental lighting conditions have led to excessive exposure to light at night (LAN), and particularly to blue wavelength lights. We hypothesized that nocturnal light exposure (i.e., dim LAN) would induce depressive responses and alter neuronal structure in hamsters (Phodopus sungorus). If this effect is mediated by ipRGCs, which have reduced sensitivity to red wavelength light, then we predicted that red LAN would have limited effects on brain and behavior compared with shorter wavelengths. Additionally, red LAN would not induce c-Fos activation in the SCN. Our results demonstrate that exposure to LAN influences behavior and neuronal plasticity and that this effect is likely mediated by ipRGCs. Modern sources of LAN that contain blue wavelengths may be particularly disruptive to the circadian system, potentially contributing to altered mood regulation.

\section{Introduction}

Endogenous circadian rhythms in physiology and behavior are synchronized to the daily solar cycle, using light as the most potent entraining cue. In mammals, ambient light is detected by the retina and signaled to the brain through retinal ganglion cells. One population, called intrinsically photosensitive retinal ganglion cells (ipRGCs), projects both to the suprachiasmatic nucleus $(\mathrm{SCN})$ in the hypothalamus, regulating circadian rhythms, and to limbic regions, putatively regulating mood (Karatsoreos and McEwen, 2011). Thus, nocturnal light exposure has the potential to affect both circadian timekeeping and mood.

Unnatural lighting, particularly exposure to electric light at night (LAN), is a relatively new phenomenon. During the past century, environmental lighting conditions have shifted from natural solar rhythms to artificial and often erratic light cycles. Exposure to LAN, and particularly blue light, has become widespread within industrialized societies (Navara and Nelson, 2007). Sources include television and computer screens, light pollution, shift work, compact fluorescent light (CFL) bulbs, and transmeridian travel. ipRGCs are maximally sensitive to blue light $(\sim 480 \mathrm{~nm})$ and minimally sensitive to red wavelength light

Received Dec. 14, 2012; revised June 12, 2013; accepted July 8, 2013.

Author contributions: T.A.B., Z.M.W., and R.J.N. designed research; T.A.B., C.A.V., A.G., and G.D. performed research; T.A.B. and C.A.V. analyzed data; T.A.B., Z.M.W., and R.J.N. wrote the paper.

This work was supported by a Department of Defense NDSEG fellowship to T.A.B. We thank Dominic Petrella for assistance with light measurements.

The authors declare no competing financial interests.

Correspondence should be addressed to Dr. Tracy A. Bedrosian, Department of Neuroscience, Ohio State University Wexner Medical Center, 636 Biomedical Research Tower, 460 W. 12th Avenue, Columbus, OH 43210. E-mail: Bedrosian.2@osu.edu.

DOI:10.1523/JNEUROSCI.5734-12.2013

Copyright $\odot 2013$ the authors $\quad 0270-6474 / 13 / 3313081-07 \$ 15.00 / 0$
$(>600 \mathrm{~nm}$ ) resulting from melanopsin expression (Lockley et al., 2003; Newman et al., 2003; Brainard et al., 2008); thus, modern sources of LAN may be particularly disruptive to circadian function.

Nighttime light results in desynchrony between the biological clock and the external environment (Bedrosian et al., 2013), which may lead to health consequences or altered mood (Healy et al., 1993). For example, nightshift workers have increased risk for mood disorders (Dumont and Beaulieu, 2007). Further, circadian abnormalities are prominent features of depressive disorders, and changes in the daily light cycle provoke depressed mood (Bunney and Bunney, 2000; McClung, 2011). Moreover, depressive responses associated with circadian disruption are related to structural changes in limbic neurons that receive ipRGC projections, such as the hippocampus (Bedrosian et al., 2011; Karatsoreos et al., 2011; Workman et al., 2011).

We hypothesized that nocturnal light exposure (i.e., dim LAN) would induce depressive-like responses and alter neuronal structure and that these effects would be mediated by melanopsin-expressing ipRGCs. Because melanopsin is minimally activated by red light, we predicted that exposure to red LAN would have less effects on the brain and behavior than shorter wavelength blue LAN, or white LAN that contains blue wavelengths. We hypothesized that red LAN would not activate melanopsin, and consequently the SCN, to the same degree as blue light. In a second experiment, we observed Fos activation of the SCN after light pulses of different wavelengths to support this hypothesis. Our experiments focus on females because many women work evening or rotating shifts (Williams, 2008), and women have a greater risk for mood disorders compared with men (Kessler et al., 1993). 


\section{Materials and Methods}

Animals. Adult female Siberian hamsters (Phodopus sungorus) from our colony at Ohio State University were individually housed in polypropylene cages $(30 \mathrm{~cm} \times 15 \mathrm{~cm} \times 14 \mathrm{~cm})$ at a constant temperature of $22 \pm$ $2^{\circ} \mathrm{C}$ and relative humidity of $50 \pm 5 \%$. Food (Harlan Teklad 8640) and filtered tap water were available ad libitum. Before the experiments, all hamsters ( $>8$ weeks of age) were ovariectomized under isoflurane anesthesia to prevent effects of cycling estrogens on neuronal morphology (Woolley and McEwen, 1992) and allowed to recover for 1 week. Then hamsters were maintained in light cycles as described below. All procedures were approved by the Ohio State University Institutional Animal Care and Use Committee and were conducted in accordance with National Institutes of Health guidelines.

Experiment 1. Experiment 1 determined the effects of chronic exposure to LAN on depressive-like behavior and hippocampal morphology. Nighttime conditions consisted of no light (dark; $N=10$ ), dim red light ( $\mathrm{rLAN} ;>600 \mathrm{~nm} ; N=10$ ), dim white light (wLAN; broad spectrum; $N=10$ ), or dim blue light (bLAN; peak at $\sim 480 \mathrm{~nm} ; N=10$ ). Hamsters were exposed to 4 weeks of experimental light before testing. All light cycles consisted of $16 \mathrm{~h}$ of bright white light ( $150 \mathrm{~lx}$; lights on at 22:00 h) and $8 \mathrm{~h}$ of either dark $(0 \mathrm{~lx})$ or dim light $(5 \mathrm{~lx})$. Light intensity was measured in the cages using a Traceable Dual Display light meter (Fisher Scientific). Both the bright and dim white lights were "cool white" fluorescent bulbs. The spectrum for the white light (GE Lighting, 10059F8T5/CW) is presented in Figure $1 A$. The dim red and dim blue lights were produced using Medium Red and Italian Blue light filters (Rosco Laboratories). Spectral transmission data were obtained from the manufacturers and are presented in Figure 1A. Homecage locomotor activity data were recorded using an infrared system (Columbus Instruments). Actigraphs were constructed using ClockLab (Actimetrics).

Behavioral assays. All behavioral testing was performed during the light phase between 08:00 and 12:00 when homecage locomotor activity levels were equivalent among groups. To assess depression-like responses (Porsolt et al., 1977), hamsters were placed in an opaque cylindrical tank filled with room-temperature water $\left(22 \pm 1^{\circ} \mathrm{C}\right)$ for $10 \mathrm{~min}$. We have previously validated the forced swim test for hamster depressive responses (Bedrosian et al., 2012a). Behavior was recorded and subsequently scored with Observer software (Noldus). The behaviors scored were as follows: (1) climbing (i.e., vigorous swimming or scratching directed at the wall of the tank), (2) swimming (i.e., horizontal movement in the tank), and (3) floating/immobility (i.e., minimal movement necessary to keep head above water surface).

Sucrose intake was assessed using methods previously described for this species (Pyter and Nelson, 2006). Briefly, baseline water intake was established by recording the water consumed for three consecutive nights. Intake was recorded over the first $5 \mathrm{~h}$ of the dark phase. Next, intake of a $3 \%$ sucrose solution was recorded over two consecutive nights and compared between groups on day 2 as a measure of anhedonia (Willner et al., 1992).

Anxiety-like behavior was assessed in the novelty-suppressed feeding test as previously described (Meshi et al., 2006). Hamsters were fooddeprived for $24 \mathrm{~h}$ and then placed into the corner of an open field (40 $\mathrm{cm} \times 40 \mathrm{~cm}$ ) containing a piece of food in the center of the arena. Behavior was videotaped for $6 \mathrm{~min}$ and then scored for latency to feed.

Social behavior was assessed using a modified social approach test. A juvenile female hamster was introduced into the homecage of the test hamster but contained within a perforated Plexiglas chamber to prevent her from approaching the test hamster or initiating any contact. Behavior was videotaped for $4 \mathrm{~min}$ and then scored for time spent investigating the juvenile and latency to first approach the juvenile.

Analysis of hippocampal morphology. Hamsters were deeply anesthetized with isoflurane and rapidly decapitated between 10:00 and 12:00 h at the conclusion of behavioral testing. Brains were quickly removed and processed for Golgi-Cox staining using a Rapid GolgiStain Kit (FD NeuroTechnologies) as previously described (Bedrosian et al., 2011). Neurons impregnated with the Golgi-Cox solution were chosen within the CA1 region of the hippocampus for analysis of dendritic spine density (Bedrosian et al., 2011). For each animal, 4-6 representative neurons were traced using Neurolucida 8 software (MicroBrightField) and a Nikon E800 microscope as described previously (Bedrosian et al., 2011).

Experiment 2. Experiment 2 determined Fos activation of the SCN by different wavelengths of LAN. A separate group of hamsters was housed in constant darkness (DD) for $3 \mathrm{~d}$ and then administered one 30 min light pulse beginning at approximately CT13. Homecage locomotor activity data were collected as described above. The light pulses consisted of bright white light $(150 \mathrm{~lx} \mathrm{~W} ; N=4)$, dim white light $(5 \mathrm{~lx} \mathrm{~W} ; N=4)$, dim red light ( $5 \mathrm{~lx} \mathrm{R} ; N=4)$, or dim blue light $(5 \mathrm{~lx} \mathrm{~B} ; N=4)$. A control group received no light pulse and remained in darkness (dark; $N=4$ ). Lights and filters were as described for Experiment 1. One hour after the start of the light pulse, hamsters were deeply anesthetized and perfused. Brains were then collected, postfixed, cryoprotected, frozen, sliced at $30 \mu \mathrm{m}$, and mounted onto gelatin-coated slides.

Fos immunohistochemistry. Sets of tissue collected at intervals of 120 $\mu \mathrm{m}$ were used for detection of Fos throughout the SCN. Briefly, sections were incubated in sodium borohydride, then rinsed with PBS, and blocked in goat serum and Triton-X. Sections were then incubated overnight at room temperature with the primary antibody (1:1000 Ab-5, Millipore). Staining was visualized with a secondary antibody and ABC$\mathrm{DAB}$ and then dehydrated and coverslipped.

Images of sections containing the SCN (bregma -0.46 to -0.58 ) were obtained at $10 \times$ magnification. Numbers of immunoreactive cells were counted in ImageJ and then averaged across sections and hemispheres. All observations were performed by an individual uninformed of assignment to groups.

Statistical analysis. Behavior and immunohistochemistry data were analyzed using independent $t$ tests and planned comparisons, with light conditions as the independent variables. Dendritic spine density was analyzed using two-way ANOVA with light and spine shape as the independent variables. Main effects were followed with Fisher's post hoc tests where applicable. Statistics were performed using Statview 5.0.1 (SAS Institute) for Windows. Mean differences were considered statistically significant when $p \leq 0.05$.

\section{Results}

\section{Experiment 1}

After 4 weeks exposure to light conditions (Fig. 1A), a variety of behavioral responses were assessed. Total homecage locomotor activity was reduced in hamsters exposed to wLAN compared with dark $\left(t_{(11)}=-3.166, p=0.009\right), \operatorname{rLAN}\left(t_{(9)}=4.111, p=\right.$ $0.003)$, and bLAN $\left(t_{(11)}=2.581, p=0.026\right)$. Exposure to rLAN increased total activity compared with dark $\left(t_{(10)}=2.371, p=\right.$ 0.039 ). This phenomenon was restricted to the night, as daytime activity levels were equivalent between groups $(p>0.05$ for all comparisons). Nighttime activity was reduced in hamsters exposed to wLAN compared with dark $\left(t_{(11)}=-3.761, p=0.003\right)$, $\operatorname{rLAN}\left(t_{(9)}=4.116, p=0.003\right)$, and bLAN $\left(t_{(11)}=2.534, p=\right.$ $0.028)$. Again, rLAN increased activity levels compared with dark $\left(t_{(10)}=2.302, p=0.044\right)$. Fast Fourier transform analysis revealed reduced power in bLAN compared with dark $\left(t_{(14)}=\right.$ 2.677, $p=0.018)$, and in bLAN $\left(t_{(13)}=3.294, p=0.006\right)$ and wLAN $\left(t_{(13)}=-2.023, p=0.032\right)$ compared with rLAN (Fig. $1 B-E)$.

Immobility in the forced swim test was analyzed as a measure of depressive-like response among hamsters exposed to the four light conditions (Fig. 2). Hamsters exposed to wLAN $\left(t_{(14)}=\right.$ 2.082, $p=0.03)$ or bLAN $\left(t_{(14)}=2.026, p=0.03\right)$ had more float bouts compared with hamsters exposed to dark. Moreover, hamsters exposed to bLAN also engaged in more float bouts than those in rLAN $\left(t_{(17)}=-1.712, p=0.05\right.$; Fig. $\left.2 A\right)$. Hamsters exposed to $\mathrm{wLAN}\left(t_{(14)}=2.159, p=0.02\right)$ or bLAN $\left(t_{(13)}=\right.$ $2.128, p=0.03$ ) spent more time immobile compared with those exposed to dark (Fig. $2 B$ ). On other measures, hamsters exposed to dark nights spent more time climbing compared with bLAN $\left(t_{(16)}=-2.274, p=0.04\right)$, with a trend toward the same when 
A
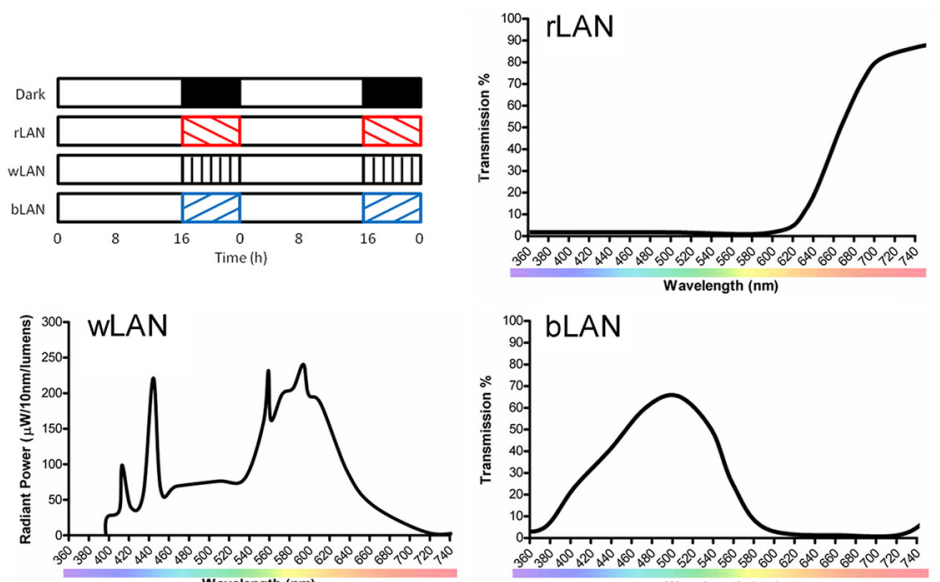

B
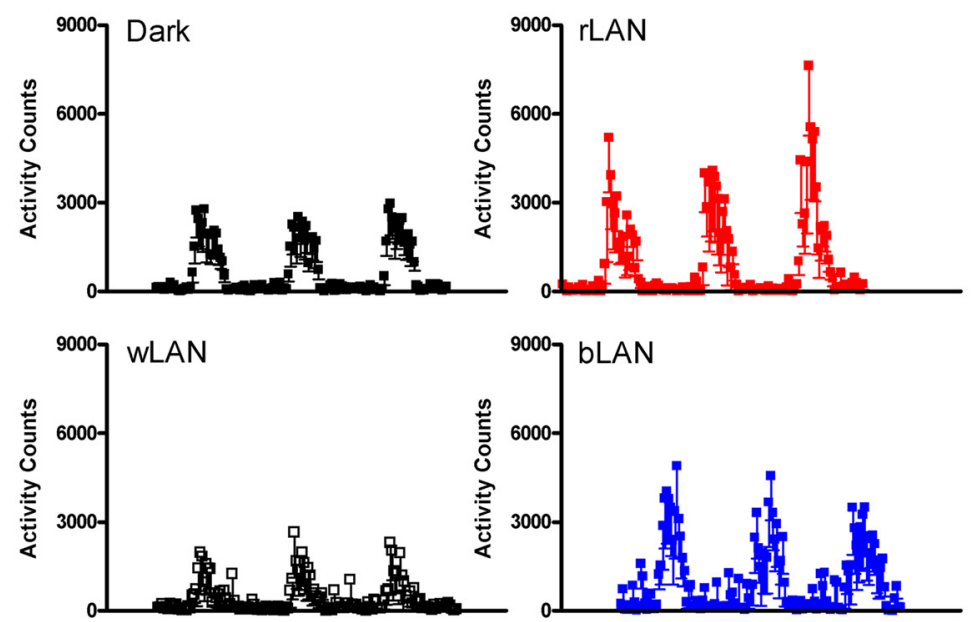

C
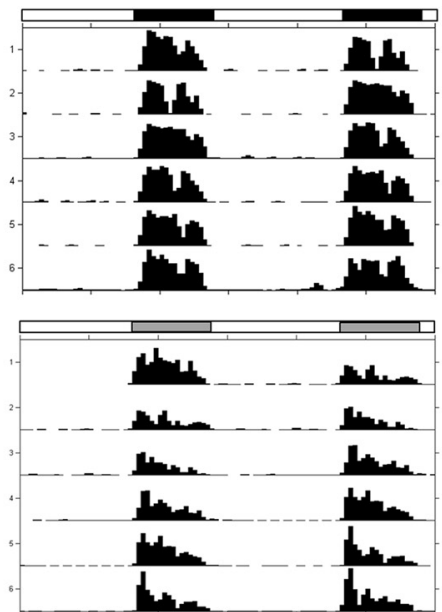

D

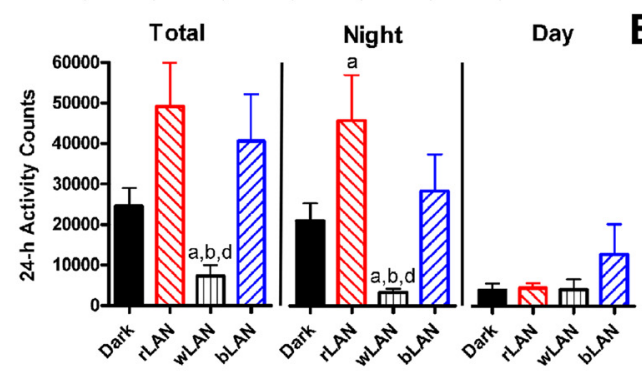

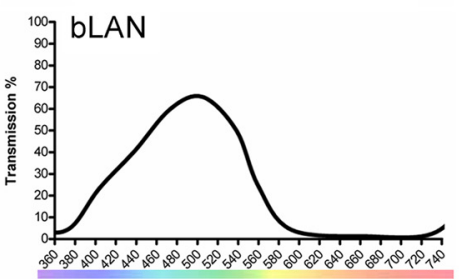

Wavelength (nm)
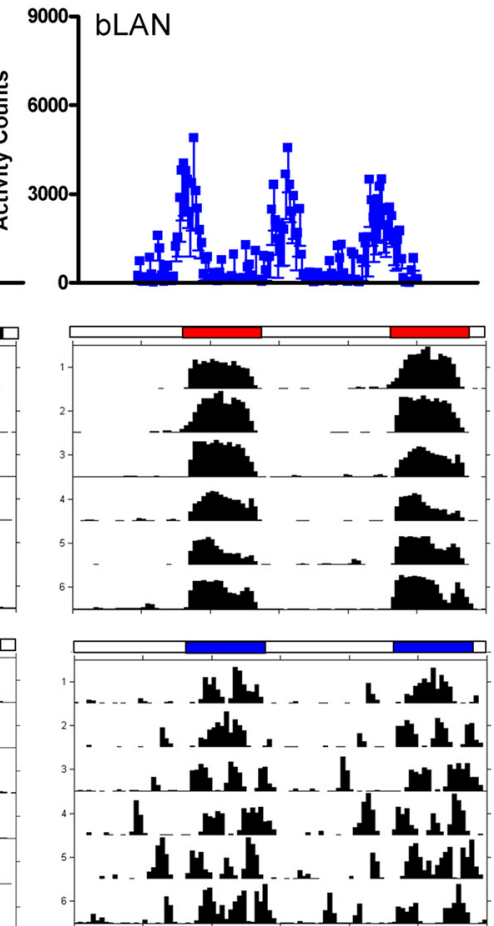

E

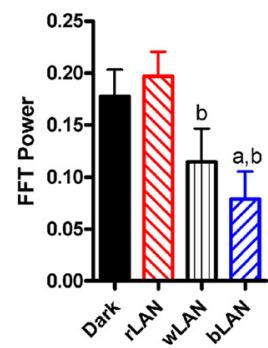

Figure 1. Nocturnal light exposure alters locomotor activity patterns. Experimental design, spectrum of light emitted from the fluorescent light sources, and transmission spectra through red and blue filters are shown $(\boldsymbol{A})$. Mean activity counts and SD over $3 \mathrm{~d}$ are presented $(\boldsymbol{B})$, along with representative actigraphs $(\boldsymbol{C})$. Total activity was reduced during exposure to white LAN, but

compared with wLAN $\left(t_{(16)}=-1.765\right.$, $p=0.09)$. Swim duration was equivalent among groups $(p>0.05)$. Hamsters exposed to wLAN had a reduced number of climbing bouts compared with dark $\left.t_{(17)}=-2.231, p=0.04\right)$ and bLAN $\left.t_{(18)}=-3.017, p=0.007\right)$, as well as reduced number of swimming bouts compared with dark $\left(t_{(17)}=-2.452, p=0.03\right)$ and $\operatorname{bLAN}\left(t_{(18)}=-3.108, p=0.006\right)$. There were no other significant differences among groups.

Sucrose intake was analyzed as a measure of anhedonic-like response. Average water intake was equivalent among groups ( $p>0.05$ for each comparison). Day 2 sucrose intake was reduced in hamsters exposed to wLAN $\left(t_{(12)}=3.567, p=\right.$ $0.004)$ and bLAN $\left(t_{(13)}=2.409, p=0.03\right)$ compared with dark. Exposure to wLAN further reduced sucrose intake compared with exposure to rLAN $\left(t_{(14)}=2.855, p=\right.$ 0.01 ) (Fig. 2C). In the novelty suppressed feeding test, there were no differences in latency to approach the food $(p>0.05)$ (Fig. 2D). In the social approach test, there were no differences in percentage time spent investigating the juvenile $(p>$ $0.05)$ or latency to approach the juvenile $(p>0.05)$ (Fig. 2E,F).

We analyzed spine density on apical and basilar dendritic branches of CA1 pyramidal neurons (Fig. 3A). Light influenced both apical $\left(F_{(3,31)}=9.936\right.$, $p<0.0001)$ and basilar $\left(F_{(3,31)}=8.827\right.$, $p<0.0001)$ dendritic spine density, with interactions between light and spine shape for apical $\left(F_{(3,31)}=2.548, p=\right.$ $0.002)$ and basilar $\left(F_{(3,31)}=2.197, p=\right.$ 0.008 ) branches. On apical dendrites, wLAN reduced total spine density compared with dark $(p=0.0006)$ and rLAN $(p=0.03)$, and similarly bLAN reduced total spine density compared with dark $(p=0.0004)$ and rLAN $(p=0.012)$. wLAN specifically reduced the density of thin spines $(p=0.03)$ and mushroom spines $(p=0.03)$ compared with hamsters exposed to dark nights. bLAN also reduced the density of thin $(p=0.04)$ and mushroom spines $(p=0.02)$ versus dark. On apical dendrites, wLAN reduced total spine density compared with dark ( $p=$ $0.01)$ and rLAN $(p=0.05)$, and similarly bLAN reduced total spine density com-

\section{$\leftarrow$}

this effect was restricted to the night, as daytime activity was equivalent between groups (D). Fast Fourier transform (FFT) revealed decreased power of the $24 \mathrm{~h}$ rhythm with exposure to white and blue LAN $(\boldsymbol{E})$. Data in $\boldsymbol{D}$ and $\boldsymbol{E}$ plotted as mean \pm SEM. ${ }^{a} p \leq 0.05$ compared with dark. ${ }^{b} p \leq 0.05$ compared with rLAN. ${ }^{d} p>0.05$ compared to bLAN. 
A

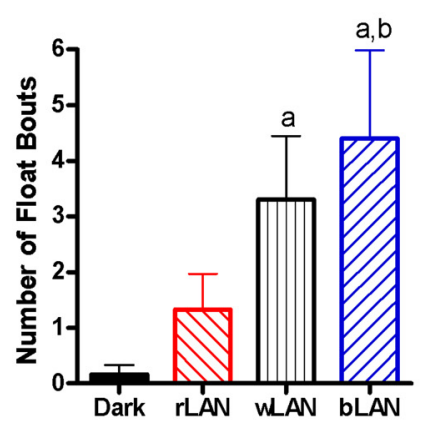

D

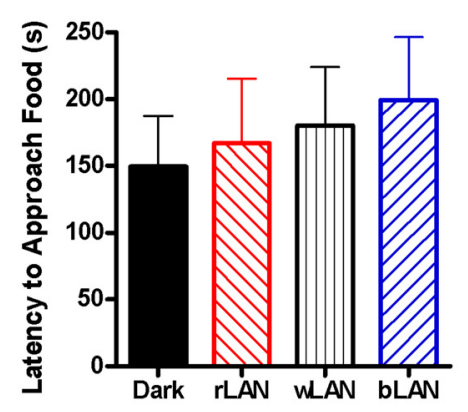

B

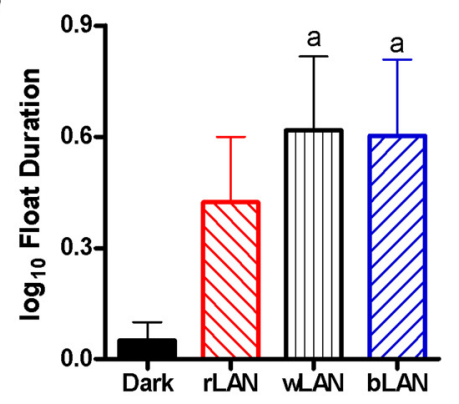

E

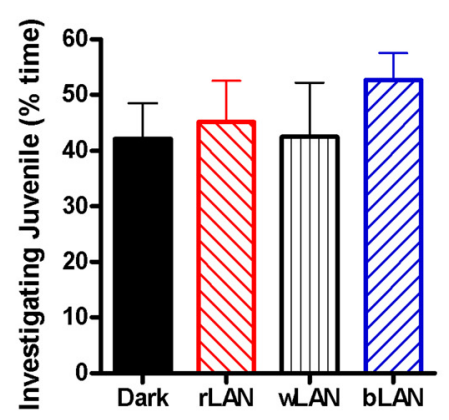

C

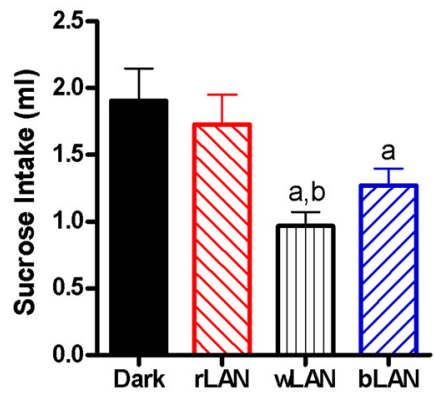

$\mathbf{F}$

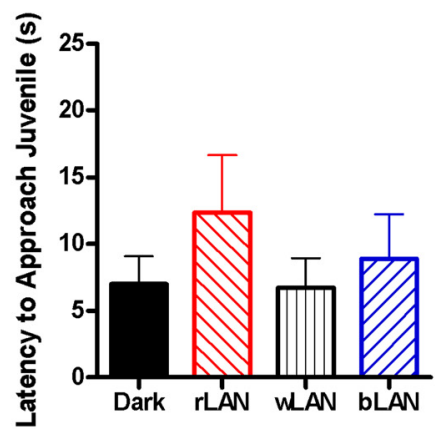

Figure 2. Nocturnal light exposure provokes depressive-like responses dependent on wavelength. Exposure to $5 \mathrm{~lx}$ white or blue LAN increased the number of float bouts $(\boldsymbol{A})$, time spent immobile in the forced swim test $(\boldsymbol{B})$, and reduced sucrose intake $(\boldsymbol{C})$. There were no differences in latency to approach food in the novelty suppressed feeding test (D), time spent investigating a juvenile hamster in the social approach test $(\boldsymbol{E})$, or latency to approach a juvenile $(\boldsymbol{F})$. Data plotted as mean \pm SEM. ${ }^{a} p \leq 0.05$ compared with dark. ${ }^{b} p \leq 0.05$ compared with rLAN.

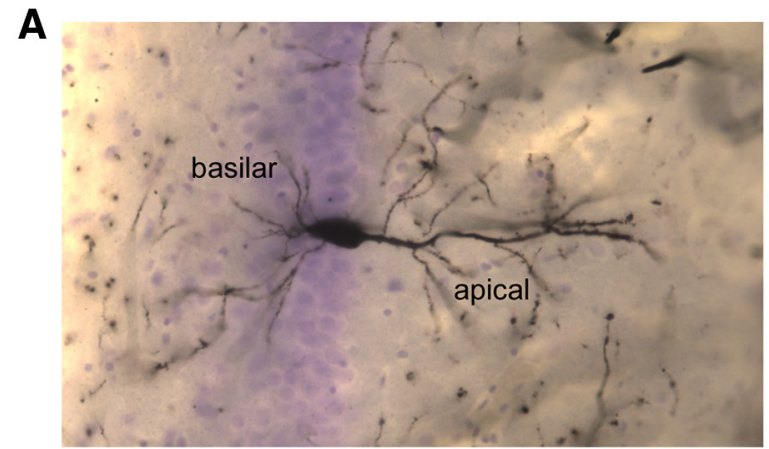

B

Dark
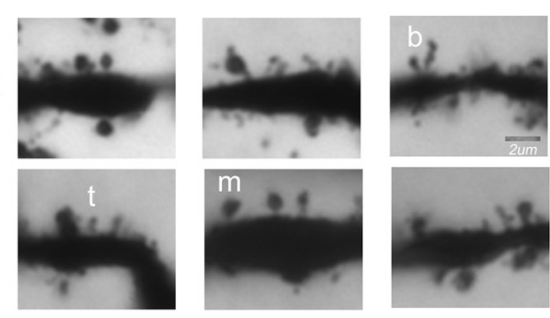

rLAN
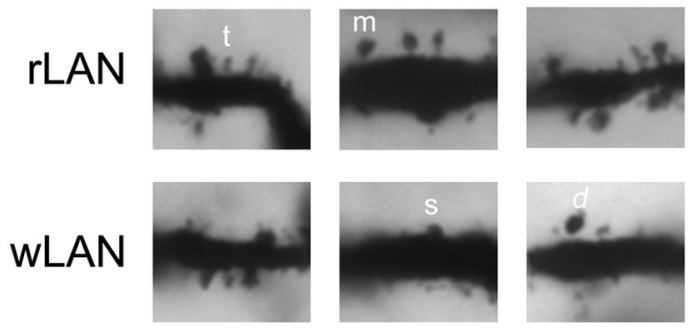

bLAN

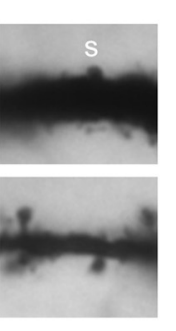

\section{C}
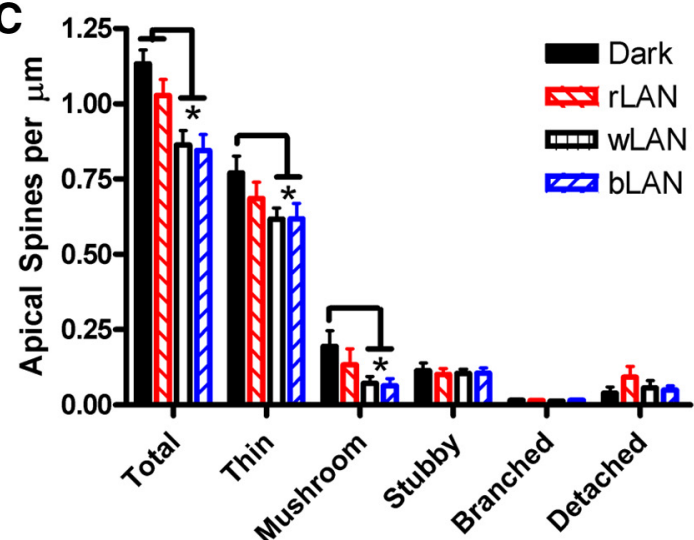

D

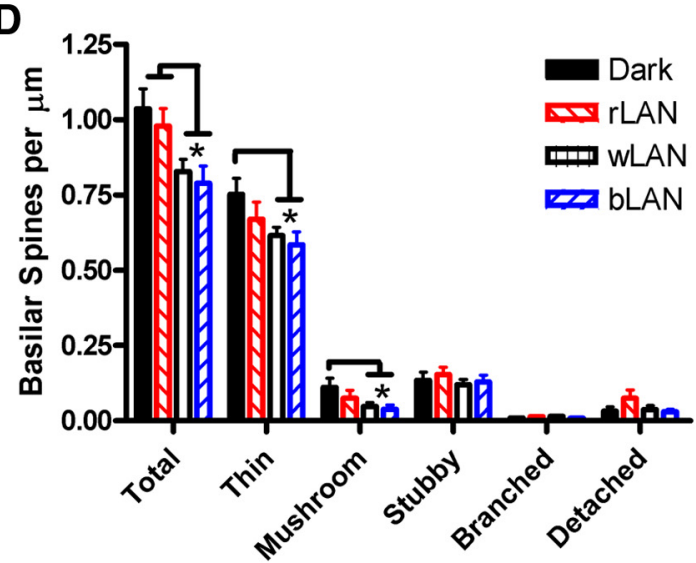

Figure 3. Nocturnal light exposure alters hippocampal neuronal morphology. Dendritic spines on both basilar and apical branches of CA1 pyramidal neurons $(\boldsymbol{A})$ were quantified based on spine shape (B). Exposure to $5 \mathrm{~lx}$ white or blue LAN reduced density of thin and mushroom spines on apical $(\boldsymbol{C})$ and basilar $(\boldsymbol{D})$ dendrites. Mean $\pm \mathrm{SEM}$. ${ }^{*} p<0.05$. t, Thin; $\mathrm{m}$, mushroom; $\mathrm{s}$, stubby; $b$, branched; d, detached. 
A

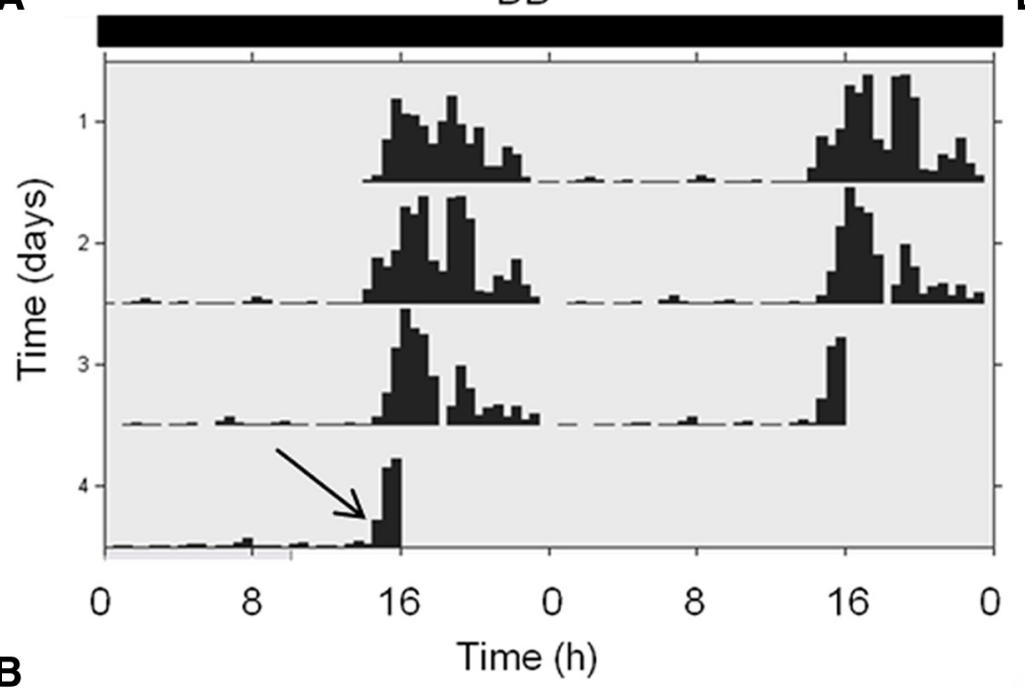

B

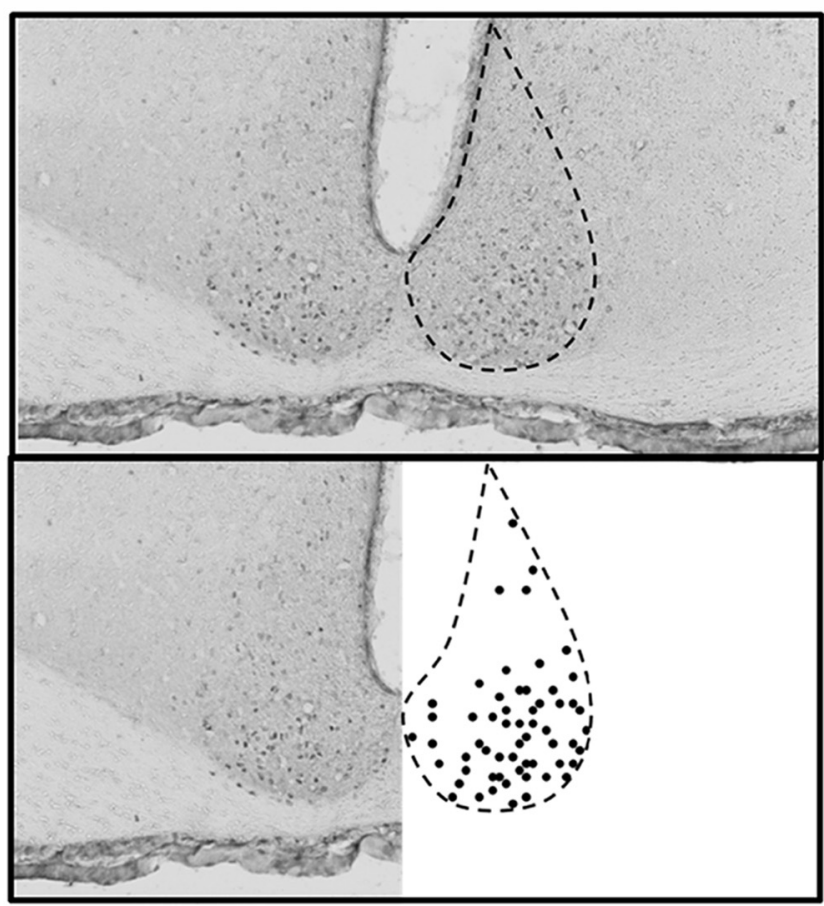

C

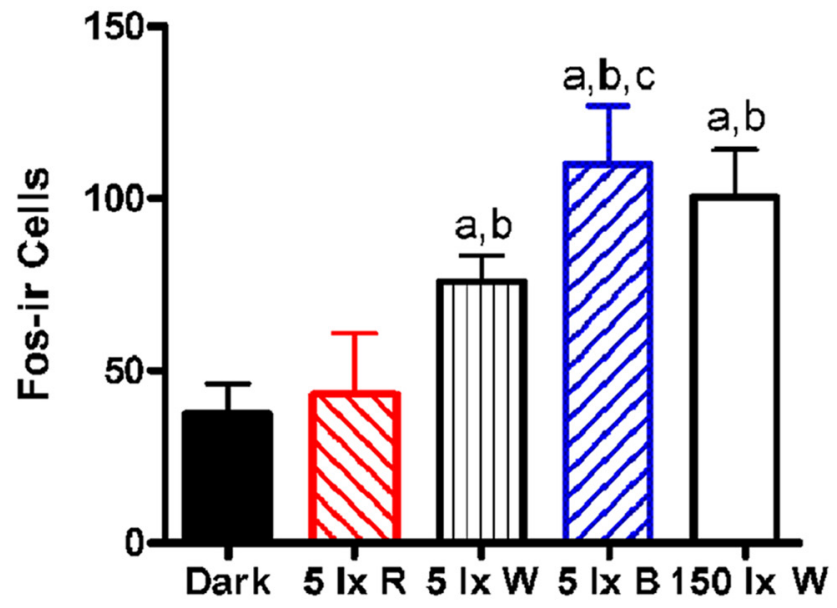

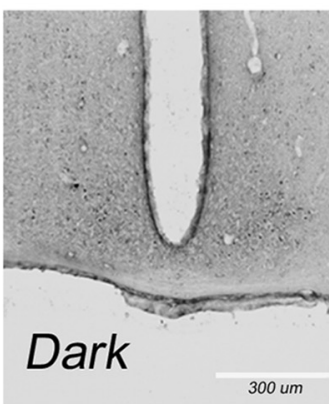
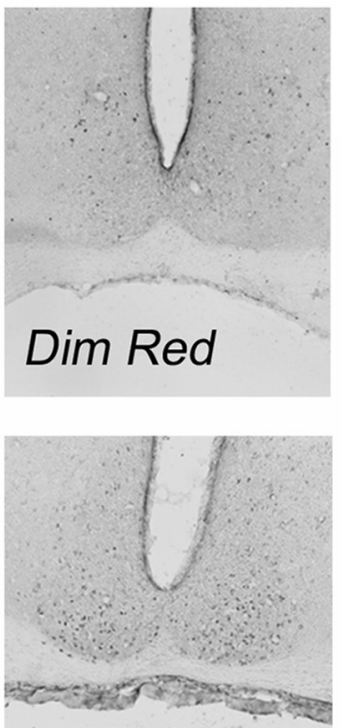

\section{Dim White}
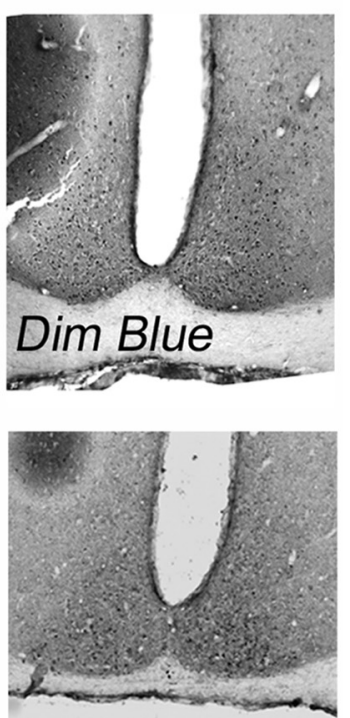

\section{Bright White}

Figure 4. Nocturnal light exposure activates the $\mathrm{SCN}$ in a wavelength-dependent manner. A 30 min light pulse administered after several days of exposure to DD ( $\boldsymbol{A})$ increased $\mathrm{C}-\mathrm{F}$ os expression immunoreactivity in the SCN (B). Exposure to 5 lx white, 5 lx blue, or $150 \mathrm{~lx}$ white light induced Fos expression, whereas red light did not $(\boldsymbol{C}, \boldsymbol{D})$. Mean \pm SEM. ${ }^{\mathrm{a}} p \leq 0.05$ compared with dark. ${ }^{\mathrm{b}} p \leq$ 0.05 compared with $5 \mathrm{IX}$ R. ${ }^{c} p \leq 0.05$ compared with $5 \mathrm{l} \times \mathrm{W}$. 
pared with dark $(p=0.004)$ and rLAN $(p=0.0228)$. wLAN specifically reduced the density of thin $(p=0.04)$ and mushroom spines ( $p=0.0426)$ compared with dark. bLAN also reduced the density of thin $(p=0.01)$ and mushroom spines $(p=0.03)$ versus dark (Fig. $3 B-D$ ).

\section{Experiment 2}

One 30 min light pulse was administered beginning at CT13 to hamsters housed in DD (Fig. 4A). Brains were collected $1 \mathrm{~h}$ after the start of the light pulse and processed for c-Fos immunoreactivity, and then positively stained cells were counted in the SCN (Franklin and Paxinos, 2007) (Fig. 4B). Fos induction was greatest in the SCN of hamsters exposed to the blue or bright white light pulses (Fig. $4 C, D$ ). The blue pulse elicited significantly greater Fos-ir compared with dark $\left(t_{(6)}=-3.844, p=0.004\right)$, red $\left.t_{(6)}=2.752, p=0.02\right)$, and dim white $\left(t_{(6)}=1.877, p=0.05\right)$. The bright white pulse elicited more Fos-ir compared with the dark $\left(t_{(5)}=4.035, p=0.005\right)$ and $\operatorname{red}\left(t_{(5)}=2.395, p=0.03\right)$ pulse.

\section{Discussion}

Nighttime light exposure has become widespread in modern societies. Our results show that LAN influences physiology and behavior and that these effects are likely mediated by ipRGCs because exposure to red LAN, to which melanopsin has little sensitivity, blocked the phenomenon.

We modeled nighttime light exposure using nocturnal rodents, but similar changes occur in diurnal rodents as well. For example, diurnal Nile grass rats exposed to $5 \mathrm{~lx}$ LAN have reduced sucrose preference, decreased latency to float in the forced swim test, and impaired learning and memory in the Barnes maze. These responses are associated with reduced dendritic length on CA1 neurons (Fonken et al., 2012). Many effects of exposure to LAN that could potentially contribute to altered behavior are evident in both nocturnal and diurnal species. Pineal melatonin secretion is robustly suppressed by LAN in both nocturnal rodents and humans (Brainard et al., 1982, 1988). However, LAN may be more likely to disrupt sleep in diurnal species that typically sleep at night versus nocturnal creatures that are active during the night. As sleep disruption has been associated with major depressive disorder in humans (Tsuno et al., 2005), it is possible that LAN may have greater effects on human mood. Alternatively, humans sleeping during exposure to LAN may be less susceptible to deleterious effects as the eyelid filters out most blue wavelengths (Ando and Kripke, 1996). It is unknown whether evening exposure during waking hours is sufficient to produce negative effects; the duration of LAN exposure necessary to provoke altered mood has not been determined. Nevertheless, these examples demonstrate that it is not unreasonable to suggest that effects of LAN observed in a nocturnal rodent model may be applicable to diurnal humans.

Nocturnal light exposure may affect mood regulating brain regions, such as the hippocampus, through projections from light detecting ipRGCs to limbic regions via the SCN (Karatsoreos and McEwen, 2011). ipRGCs are maximally sensitive to blue light $(\sim 480 \mathrm{~nm})$ and minimally sensitive to red wavelength light $(>600 \mathrm{~nm})$ (Newman et al., 2003). Melanopsin expression results in wavelength-dependent activation of membrane currents through the $\mathrm{G}_{\mathrm{q} / 11}$ signaling pathway, and melanopsin possesses intrinsic photoisomerase function shifted toward the red wavelengths (Melyan et al., 2005; Panda et al., 2005). Blue LAN, and white LAN which contains blue wavelengths, induced greater Fos expression in the SCN compared with red LAN or darkness, dem- onstrating that the levels of blue and white light exposure used in this experiment activate ipRGCs and the SCN. This activation by LAN is inappropriately timed and may lead to changes affecting the projection targets of the $\mathrm{SCN}$, such as limbic regions (e.g., the hippocampus). Indeed, evidence suggests that blue wavelength light in particular can influence the hippocampus. Exposure to blue light increases human hippocampal activity compared with longer wavelength green light, and the differences are detectable almost immediately after light onset (Vandewalle et al., 2007). This provides evidence that light is a modulator of cognitive brain function in humans (Vandewalle et al., 2009).

We investigated structural plasticity of the hippocampus in response to chronic LAN exposure. Neurotrophic support, in particular expression of BDNF, is reduced in the hippocampi of rodents exposed to LAN (Bedrosian et al., 2012b). Further, dendritic spines are highly plastic and may change rapidly in response to cues from the environment (Fischer et al., 1998). We measured dendritic spine density on segments $>50 \mu \mathrm{m}$ from the cell body so as to capture the primary sites of excitatory neuronal input (Megias et al., 2001; von Bohlen Und Halbach, 2009). We also analyzed spines based on shape, as this provides information about the strength and maturity of the associated synapse (Yoshihara et al., 2009). Spine density was reduced after exposure to blue or white LAN, and the effect was driven by reductions in mushroom and thin spines. This raises the possibility that LAN exposure reduces spine formation, as thin spines are thought to be young and possibly involved in learning and cognition (Yoshihara et al., 2009). LAN also impairs performance in learning and memory tasks in rodents (Fonken et al., 2012).

Our results demonstrate an important role for nocturnal light exposure in mood and point to broader implications of modern lighting on the brain and behavior. Computers, televisions, e-readers, and CFL bulbs emit blue light, and nighttime use is widespread. Our results highlight the importance of wavelength in mood-related responses to light. This should direct efforts to minimize the deleterious effects of aberrant light exposure through manipulation of wavelength.

\section{References}

Ando K, Kripke DF (1996) Light attenuation by the human eyelid. Biol Psychiatry 39:22-25. CrossRef Medline

Bedrosian TA, Fonken LK, Walton JC, Haim A, Nelson RJ (2011) Dim light at night provokes depression-like behaviors and reduces CAl dendritic spine density in female hamsters. Psychoneuroendocrinology 36:10621069. CrossRef Medline

Bedrosian TA, Weil ZM, Nelson RJ (2012a) Chronic citalopram treatment ameliorates depressive behavior associated with light at night. Behav Neurosci 126:654-658. CrossRef Medline

Bedrosian TA, Weil ZM, Nelson RJ (2012b) Chronic dim light at night provokes reversible depression-like phenotype: possible role for TNF. Mol Psychiatry. Advance online publication. Retrieved July 24, 2012. doi: 10.1038/mp.2012.96. CrossRef Medline

Bedrosian TA, Galan A, Vaughn CA, Weil ZM, Nelson RJ (2013) Light at night alters daily patterns of cortisol and clock proteins in female Siberian hamsters. J Neuroendocrinol 25:590-606. CrossRef Medline

Brainard GC, Richardson BA, Petterborg LJ, Reiter RJ (1982) The effect of different light intensities on pineal melatonin content. Brain Res 233:75-81. CrossRef Medline

Brainard GC, Lewy AJ, Menaker M, Fredrickson RH, Miller LS, Weleber RG, Cassone V, Hudson D (1988) Dose-response relationship between light irradiance and the suppression of plasma melatonin in human volunteers. Brain Res 454:212-218. CrossRef Medline

Brainard GC, Sliney D, Hanifin JP, Glickman G, Byrne B, Greeson JM, Jasser S, Gerner E, Rollag MD (2008) Sensitivity of the human circadian system to short-wavelength (420-nm) light. J Biol Rhythms 23:379-386. CrossRef Medline

Bunney WE, Bunney BG (2000) Molecular clock genes in man and lower 
animals: possible implications for circadian abnormalities in depression. Neuropsychopharmacology 22:335-345. CrossRef Medline

Dumont M, Beaulieu C (2007) Light exposure in the natural environment: relevance to mood and sleep disorders. Sleep Med 8:557-565. CrossRef Medline

Fischer M, Kaech S, Knutti D, Matus A (1998) Rapid actin-based plasticity in dendritic spines. Neuron 20:847-854. CrossRef Medline

Fonken LK, Kitsmiller E, Smale L, Nelson RJ (2012) Dim nighttime light impairs cognition and provokes depressive-like responses in a diurnal rodent. J Biol Rhythms 27:319-327. CrossRef Medline

Franklin KBJ, Paxinos G (2007) The mouse brain in stereotaxic coordinates. Ed 3. San Diego: Elsevier.

Healy D, Minors DS, Waterhouse JM (1993) Shiftwork, helplessness and depression. J Affect Disord 29:17-25. CrossRef Medline

Karatsoreos IN, McEwen BS (2011) Psychobiological allostasis: resistance, resilience and vulnerability. Trends Cogn Sci 15:576-584. CrossRef Medline

Karatsoreos IN, Bhagat S, Bloss EB, Morrison JH, McEwen BS (2011) Disruption of circadian clocks has ramifications for metabolism, brain, and behavior. Proc Natl Acad Sci U S A 108:1657-1662. CrossRef Medline

Kessler RC, McGonagle KA, Swartz M, Blazer DG, Nelson CB (1993) Sex and depression in the National Comorbidity Survey: I. Lifetime prevalence, chronicity and recurrence. J Affect Disord 29:85-96. CrossRef Medline

Lockley SW, Brainard GC, Czeisler CA (2003) High sensitivity of the human circadian melatonin rhythm to resetting by short wavelength light. J Clin Endocrinol Metab 88:4502-4505. CrossRef Medline

McClung CA (2011) Circadian rhythms and mood regulation: insights from pre-clinical models. Eur Neuropsychopharmacol 21 [Suppl 4]:S683-S693.

Megías M, Emri Z, Freund TF, Gulyás AI (2001) Total number and distribution of inhibitory and excitatory synapses on hippocampal CA1 pyramidal cells. Neuroscience 102:527-540. CrossRef Medline

Melyan Z, Tarttelin EE, Bellingham J, Lucas RJ, Hankins MW (2005) Addition of human melanopsin renders mammalian cells photoresponsive. Nature 433:741-745. CrossRef Medline

Meshi D, Drew MR, Saxe M, Ansorge MS, David D, Santarelli L, Malapani C, Moore H, Hen R (2006) Hippocampal neurogenesis is not required for behavioral effects of environmental enrichment. Nat Neurosci 9:729-731. CrossRef Medline
Navara KJ, Nelson RJ (2007) The dark side of light at night: physiological, epidemiological, and ecological consequences. J Pineal Res 43:215-224. CrossRef Medline

Newman LA, Walker MT, Brown RL, Cronin TW, Robinson PR (2003) Melanopsin forms a functional short-wavelength photopigment. Biochemistry (Mosc) 42:12734-12738. CrossRef Medline

Panda S, Nayak SK, Campo B, Walker JR, Hogenesch JB, Jegla T (2005) Illumination of the melanopsin signaling pathway. Science 307:600-604. CrossRef Medline

Porsolt RD, Bertin A, Jalfre M (1977) Behavioral despair in mice: a primary screening test for antidepressants. Arch Int Pharmacodyn Ther 229:327-336. Medline

Pyter LM, Nelson RJ (2006) Enduring effects of photoperiod on affective behaviors in Siberian hamsters (Phodopus sungorus). Behav Neurosci 120:125-134. CrossRef Medline

Tsuno N, Besset A, Ritchie K (2005) Sleep and depression. J Clin Psychiatry 66:1254-1269. CrossRef Medline

Vandewalle G, Schmidt C, Albouy G, Sterpenich V, Darsaud A, Rauchs G, Berken PY, Balteau E, Degueldre C, Luxen A, Maquet P, Dijk DJ (2007) Brain responses to violet, blue, and green monochromatic light exposures in humans: prominent role of blue light and the brainstem. PLoS One 2:e1247. CrossRef Medline

Vandewalle G, Maquet P, Dijk DJ (2009) Light as a modulator of cognitive brain function. Trends Cogn Sci 13:429-438. CrossRef Medline

von Bohlen Und Halbach O (2009) Structure and function of dendritic spines within the hippocampus. Ann Anat 191:518-531. CrossRef Medline

Williams C (2008) Work-life balance of shift workers. Perspectives (Montclair). Ottawa, Ontario: Statistics Canada.

Willner P, Muscat R, Papp M (1992) An animal model of anhedonia. Clin Neuropharmacol 15 [Suppl 1]:550A-551A.

Woolley CS, McEwen BS (1992) Estradiol mediates fluctuation in hippocampal synapse density during the estrous cycle in the adult rat. J Neurosci 12:2549-2554. Medline

Workman JL, Manny N, Walton JC, Nelson RJ (2011) Short day lengths alter stress and depressive-like responses, and hippocampal morphology in Siberian hamsters. Horm Behav 60:520-528. CrossRef Medline

Yoshihara Y, De Roo M, Muller D (2009) Dendritic spine formation and stabilization. Curr Opin Neurobiol 19:146-153. CrossRef Medline 